\title{
How Maize Seeds and Seedlings Cope with Oxygen Deficit
}

\author{
B. Greg Cobb, Malcolm C. Drew, David L. Andrews, James Johnson, David M. MacAlpine, \\ Tricia L. Danielson, and Meredith A. Turnbough \\ Department of Horticultural Sciences, Texas A\&M University, College Station, TX 77843
}

\author{
Ronald Davis \\ Department of Medical Anatomy, Texas A\&M University, College Station, TX 77843
}

\begin{abstract}
When flooding occurs, the $\mathrm{O}_{2}$ concentration in the soil declines gradually (Blackwell, 1983) and roots undergo a period of hypoxia before $\mathrm{O}_{2}$ is fully depleted from the soil and anoxia is reached. (We use the terms hypoxia and anoxia as described by Pradet and Bomsel (1978). Hypoxia is a condition in which the concentration of $\mathrm{O}_{2}$ limits ATP production in the mitochondria. Anoxia is defined as a condition in which the concentration of $\mathrm{O}_{2}$ is so low that virtually no ATP is produced by the mitochondria.) When these conditions are simulated in the laboratory, by pretreating roots with low $\mathrm{O}_{2}$ before subjecting them to anoxia, root tips survive longer than those made anoxic without a hypoxic pretreatment. This response was first described by Saglio et al. (1988) and has been termed "hypoxic acclimation."

There is a pronounced difference in the responses of acclimated and unacclimated seminal maize (Zea mays L.) roots to anoxia. At the onset of anoxia, energy production declines, there is acidosis of the cytoplasm, and cell death occurs within 15 to $20 \mathrm{~h}$ (Johnson et al., 1989; Roberts et al., 1984a, 1984b; Saglio et al., 1988). Thus, after 24 h of anoxia, there is little remaining cellular organization of unacclimated root tip cells. The only recognizable organelle is the nucleus (Fig. 1). In contrast, acclimated root tips survive $96 \mathrm{~h}$ of anoxia (Johnson et al., 1989). Acclimated root tips subjected to anoxia appear to maintain normal cellular organization through $48 \mathrm{~h}$ (Fig. 1) and possess higher ATP concentrations and higher rates of anaerobic metabolism than unacclimated root tips (Hole et al., 1992; Johnson et al., 1989; Saglio et al., 1988).

Clearly, hypoxia induces physiological responses that give rise to improved resistance to anoxia, and the identification of those responses has been the focus of research for several years. The present report discusses the role of hypoxia in the induction of anaerobic metabolism. This is not intended to be a general review of the response of plants to $\mathrm{O}_{2}$ deficit (for such a review, see Kennedy et al., 1992; Ricard et al., 1994). We first examine how different methodologies to induce $\mathrm{O}_{2}$ deficit can give rise to contrasting conclusions. Second, we present data suggesting that seeds and young seedlings are more resistant to anoxia than older seedlings. We conclude with a review of our data and those of others concerning the role of hypoxia in extending survival of anoxia in maize seminal root tips.
\end{abstract}

\section{METHODS OF INDUCING $\mathrm{O}_{2}$ STRESS}

While the anaerobic response of maize has been the subject of extensive study (reviewed in Bailey-Serres et al., 1988), a wide variety of methods have been used to induce $\mathrm{O}_{2}$ deficit. In general, germinated seedlings of varying ages are completely immersed in solutions that are either left open to the air, sealed without sparging, or sparged with gases (for examples, see Hwang and VanToai, 1991; Peschke and Sachs, 1994; Rowland and Strommer, 1986; Russell and Sachs, 1992; Sachs et al., 1980). Interestingly, the method that is used to induce $\mathrm{O}_{2}$ stress can result in measurable differences in the extent and localization of the response.

There is evidence that cells within the root apical meristem, where respiration rates are high, can be subjected to a mild hypoxia when grown at ambient $\mathrm{O}_{2}$ concentrations at room temperature (Andrews et

Received for publication 17 Mar. 1995. Accepted for publication 8 Apr. 1995 Research supported by U.S. Dept. of Agriculture Competitive Grant no. 9037264-5523 and 93-37100-8922. The cost of publishing this paper was defrayed in part by the payment of page charges. Under postal regulations, this paper therefore must be hereby marked advertisement solely to indicate this fact. al., 1993). Our method is to pretreat seedlings by sparging with $40 \%$ $\mathrm{O}_{2}$ for $18 \mathrm{~h}$ to ensure that they are fully aerobic before the onset of the experimental hypoxic treatment, anoxic treatment, or both. Seedlings are not immersed, but are placed on floats in containers so that the roots, but not the shoots, are immersed in solution. The containers are then sealed and continuously sparged with gas of known composition. Thus, even though the shoots are not submerged, they are exposed to the same gaseous atmosphere as the roots. For the hypoxic pretreatment (HPT), seedlings are sparged with $4 \% \mathrm{O}_{2}$ for $18 \mathrm{~h}$ before the anoxic treatment. Seedlings that are not hypoxically pretreated (NHPT) are transferred directly from $40 \%$ to $0 \% \mathrm{O}_{2}\left(100 \% \mathrm{~N}_{2}\right)$.

Alcohol dehydrogenase has long been used as a marker for fermentation and we have compared the induction of its message ( $a d h l$ ) using our methods with those used by other researchers. Both submerged and NHPT-treated plants show a similar response in root tips and root axes (Fig. 2). There is little $a d h 1$ transcript in root tips in submerged or NHPT plants at $24 \mathrm{~h}$ of treatment (Fig. 2), but there is induction in the root axes. The root tips of HPT seedlings contain a higher concentration of $a d h 1$ transcript after $24 \mathrm{~h}$ than root axes or shoots. This result suggests that, when seedlings are submerged in a buffer solution, the dissolved $\mathrm{O}_{2}$ is depleted at a higher rate than necessary for hypoxic acclimation to occur. However, note that the seedlings for the immersion treatment had been pretreated with $40 \% \mathrm{O}_{2}$. As already noted, root tips of maize seedlings that are maintained at $25 \mathrm{C}$ in $21 \% \mathrm{O}_{2}$ are already under hypoxia (Andrews et al., 1993) so that seedlings that had not been pretreated with $40 \% \mathrm{O}_{2}$ before immersion probably more closely mimic the HPT treatment.

Although the root tips die, the root axes of NHPT plants survived more than $24 \mathrm{~h}$ of anoxia (Fig. 2) and have survived as long as $70 \mathrm{~h}$ (Sachs et al., 1980). We have found that the zone of maximal ADH activity in the seminal root is not uniform and changes during $24 \mathrm{~h}$ of anoxia (Fig. 3). Primary root axes, $8 \mathrm{~cm}$ long, were divided into $2-\mathrm{cm}$ segments after the $0.5-\mathrm{mm}$ root tips sections had been removed, and $\mathrm{ADH}$ activity then was determined in each segment during $24 \mathrm{~h}$ of anoxia (Fig. 3). At time 0, corresponding to the $18-\mathrm{h} 40 \% \mathrm{O}_{2}$ pretreatment, there was a slightly higher level of ADH enzyme activity in the root axes than in the root tips. During anoxia, there was a transient rise in $\mathrm{ADH}$ activity in the root tip through $6 \mathrm{~h}$; then activity declined to near 0 at $18 \mathrm{~h}$. The 2 -cm section adjacent to the root tips exhibited a decline throughout the treatment; however, ADH activity increased in the more distal segments of the root through $24 \mathrm{~h}$.

\section{RESPONSE OF SEEDS AND YOUNG SEEDLINGS TO ANOXIA}

In most of our work, we have used root tips from roots that are 8 to $10 \mathrm{~cm}$ long ( $\approx 5$ days after germination). Recently, we compared the response of these root tips (L) with that of root tips from shorter roots (S) ( $\approx 3$ days after germination). Interestingly, $S$ roots did not need a hypoxic pretreatment to survive $12 \mathrm{~h}$ of anoxia, whereas L root tips required $18 \mathrm{~h}$ of hypoxia to survive (Andrews et al., 1994b). This finding has lead us to examine the response of unimbibed seeds and germinating seeds to anoxia. In this experiment, unimbibed maize seeds or seeds that had germinated for 1,2 , or 3 days were placed in anoxia for 2, 4, or 6 days, then returned to ambient air. Survival was gauged as the ability of the roots to resume growth. While they did not germinate during the anoxic treatment, seeds that were imbibed during anoxia germinated when returned to air (Table 1) and retained this ability even after 10 days of anoxia (data not shown). Leblova (1978) suggested that imbibed, germinated seeds in general are anaerobic 


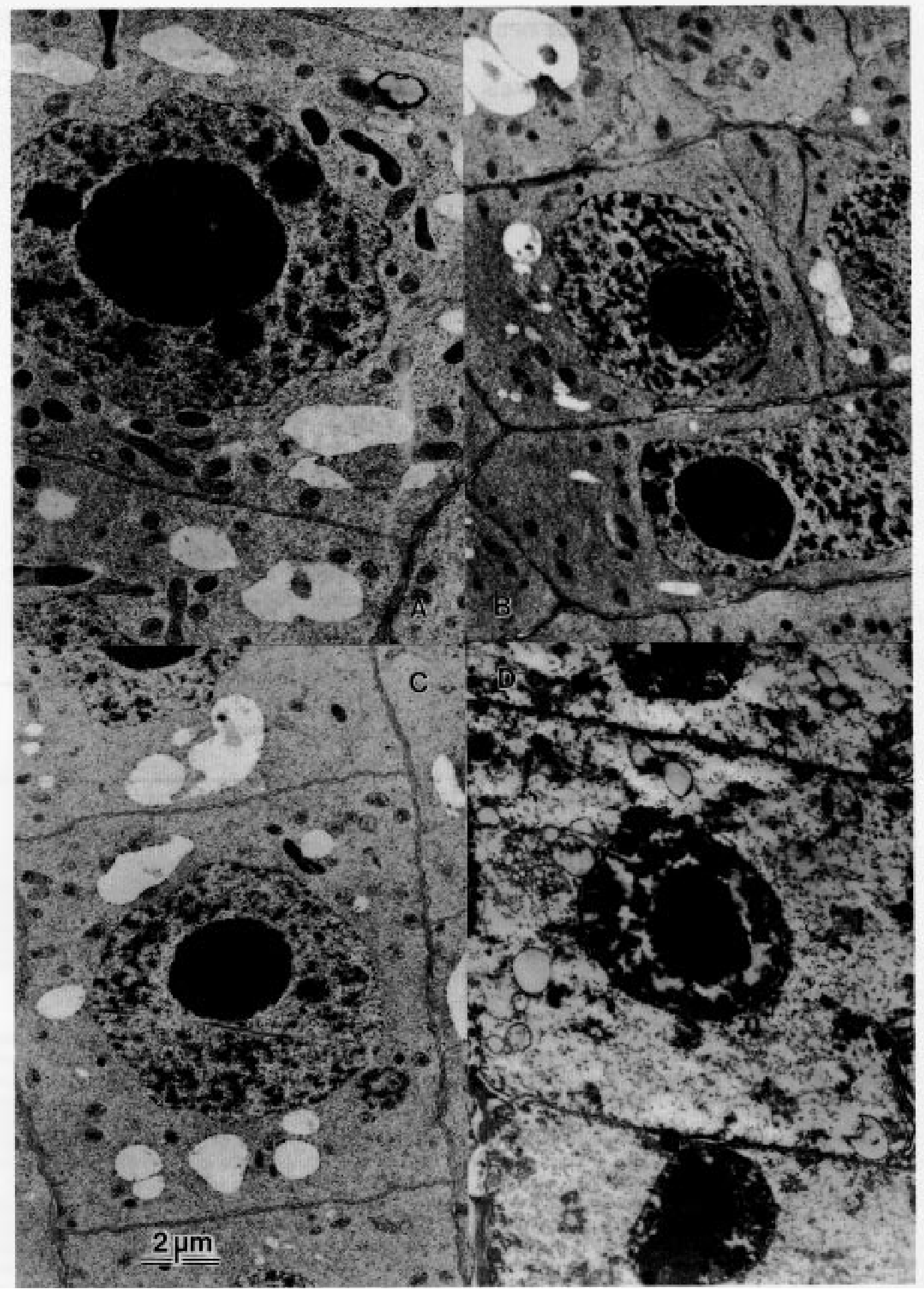

Fig. 1. Electron micrographs of maize root cells $(\times 7200)$. (A) Hypoxic pretreatment (HPT) after $24 \mathrm{~h}$ of anoxia; (B) HPT after $48 \mathrm{~h}$ anoxia; (C) after the $18 \mathrm{~h} \mathrm{HPT}$; (D) Nonhypoxically pretreated (NHPT) maize root tip cells after $24 \mathrm{~h}$ of anoxia. All are sections from the central core of the meristematic zone.

until radicle emergence. While this observation is not accurate for all seeds, maize seeds are known to have a relative high rate of fermentation in air and can germinate at low $\mathrm{O}_{2}$ concentrations (Al-Ani et al., 1985; Raymond et al., 1985). Since they did not germinate during anoxia, perhaps maize caryopses extend the anaerobic period of germination until $\mathrm{O}_{2}$ is present and germination can proceed.
Caryopses that were germinated in air for 1 to 3 days survived at least 2 days of anoxia (Table 1). Seeds that were germinated for 3 days before anoxia survived anoxia for only 2 days. This decline in survival coincides with root emergence, which occurs between 2 to 3 days at $25 \mathrm{C}$. Therefore, while very young roots are more resistant to anoxia than are roots from older seedlings, they are not nearly as resistant as seeds. 


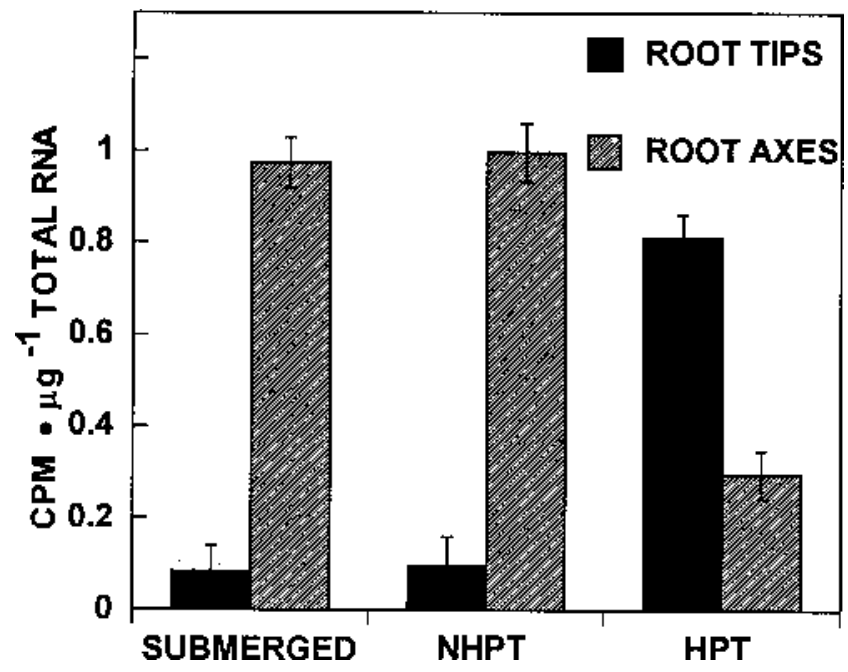

Fig. 2. Adh1 mRNA levels (as cpm $\mu \mathrm{g}^{-1}$ total RNA) in root tips, root axes, and shoots of maize seedlings using two methods to induce $\mathrm{O}_{2}$ stress. For the submerged treatment, seedlings were first pretreated with $40 \% \mathrm{O}_{2}$, then completely submerged in a beaker filled with a buffered solution. The solution was neither sparged nor the beaker sealed for $24 \mathrm{~h}$. Nonhypoxic pretreatment and hypoxic pretreatment were as described in the text.

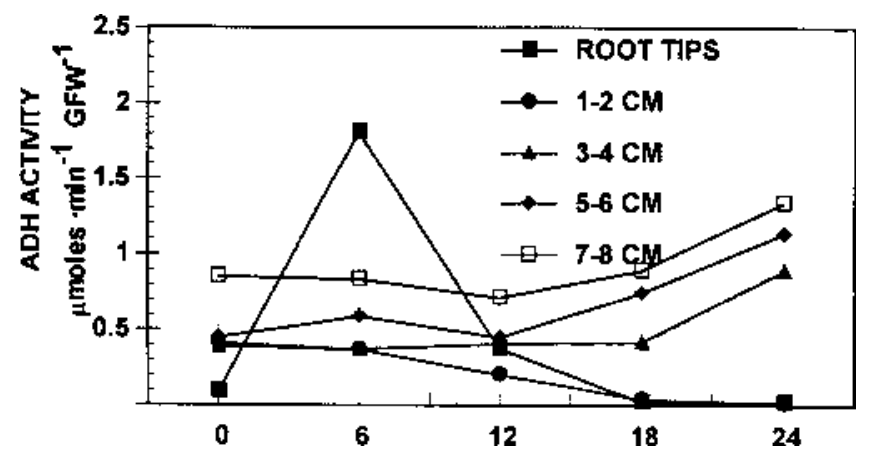

Fig. 3. Distribution of ADH activity during $24 \mathrm{~h}$ of anoxia of nonhypoxically pretreated maize seminal roots. Distances from root tip.

\section{ROLE OF HYPOXIA IN INDUCING FERMENTATION}

Oxidative phosphorylation is minimal when $\mathrm{O}_{2}$ is limited and roots must maintain ATP production through glycolysis-fermentation (Johnson et al., 1989; Roberts et al., 1989; Saglio et al., 1980). ATP production through these pathways is too limited to sustain root growth (net yield is $2 \mathrm{~mol} \mathrm{ATP} / \mathrm{mol}$ glucose for fermentation vs. $\approx 36$ by oxidative phosphorylation), and extended periods of $\mathrm{O}_{2}$ stress result in cell injury and, subsequently, death (Drew, 1988; Jackson and Drew, 1984; Saglio et al., 1984). In plants, the major product of fermentation is ethanol (Smith and Ap Rees, 1979), although conversion of pyruvate to lactate under anoxia does occur and may play a critical role in hypoxia-induced anoxia tolerance. The pathways for these conversions are summarized in Fig. 4. Briefly, pyruvate can be converted into lactate by lactate dehydrogenase (LDH). Alternately, pyruvate is converted by pyruvate decarboxylase (PDC) to acetaldehyde and then by alcohol dehydrogenase (ADH1 and $\mathrm{ADH} 2)$ to ethanol. ADH1 specific activity is 10- to 20-fold higher than that of $\mathrm{ADH} 2$ and is the predominant enzyme that catalyzes this reaction (Freeling and Bennett, 1985; Sachs et al., 1985).

\section{Induction of ethanolic fermentation}

A key feature that occurs during hypoxia is the induction of the ethanolic fermentative pathway (Hole et al., 1992; Xia and Saglio, 1992). After $18 \mathrm{~h}$ of $\mathrm{HPT}, \approx 75 \%$ of the $\mathrm{CO}_{2}$ produced in an atmosphere
Table 1. Survival of seeds after exposure to anoxia for 2,4 , or 6 days. Seeds were germinated in petri dishes in distilled water at $25 \mathrm{C}$ for either 1,2 , or 3 days before transfer into anoxia. For 0 time, unimbibed seeds were placed in an anaerobic workbench before distilled water (sparged with nitrogen) was added. After the anoxic treatment, seeds were returned to ambient air and survival was based on the ability of the seeds to germinate or on regrowth of roots. Roots emerged between 1 and 2 days of germination and root length at 3 days was $\approx 1 \mathrm{~cm}$. In comparison, average root length of seedlings following germination at $28 \mathrm{C}$ is $\approx 5 \mathrm{~cm}$ after 3 days.

\begin{tabular}{lccr}
\hline $\begin{array}{l}\text { Days of } \\
\text { germination } \\
\text { before anoxia }\end{array}$ & \multicolumn{3}{c}{ Days in anoxia } \\
\cline { 2 - 4 } & 2 & 4 & 6 \\
\hline & & Germination $(\%)$ \\
1 & $98.1 \pm 3.2$ & $90.2 \pm 4.6$ & $91.3 \pm 7.6$ \\
2 & $81.5 \pm 5.3$ & $88.3 \pm 8.2$ & $52.6 \pm 7.9$ \\
3 & $76.4 \pm 6.1$ & $66.5 \pm 5.9$ & $13.2 \pm 8.2$ \\
\hline
\end{tabular}

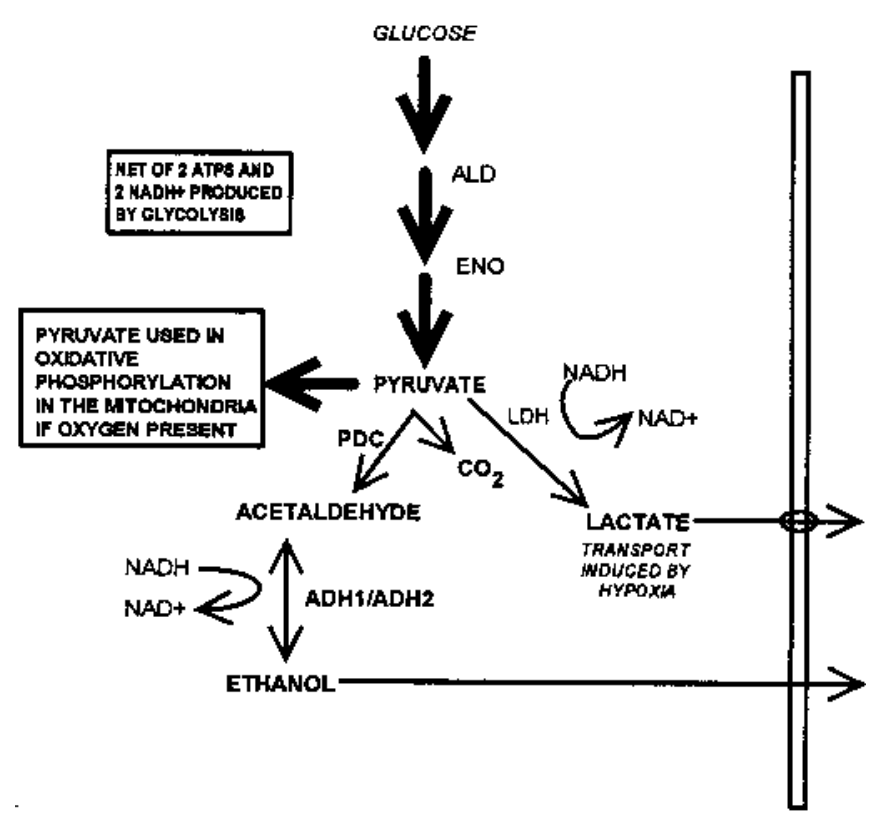

Fig. 4. Overview of ethanolic and lactate fermentative pathways. Thick arrows mark the normal flow of carbon through oxidative phosphorylation. During hypoxia there is an induction of a sustained ethanolic fermentation (thin arrows). Whereas ethanol can freely diffuse from cells, lactate cannot and hypoxia appears to induce a transport mechanism to remove lactate from the cells (Xia and Roberts, 1994).

of $4 \% \mathrm{O}_{2}$ can be accounted for through fermentation by excised maize root tips (Table 2). Both HPT and NHPT root tips show similar initial increases in the rate of glycolysis and ethanol production during the first hour of anoxia (Hole et al., 1992). However, HPT root tips can sustain a higher rate of ethanol production than NHPT root tips (Hole et al., 1992; Xia and Saglio, 1992). Additionally, HPT root tips from intact maize plants have higher levels of ATP and total adenylates than do NHPT root tips (Johnson et al., 1989).

All of these data indicate that fermentation is induced during hypoxia, and it is not surprising that genes involved in either carbohydrate metabolism, glycolysis, or fermentation have been identified as being among those induced by anaerobic stress. These genes include those for glucose phosphate isomerase (Kelley and Freeling, 1984a), pyruvate decarboxylase $(p d c)$ (Kelley, 1989; Laszlo and Lawrence, 1983), glyceraldehyde-3-phosphate dehydrogenase ( gpc 3 \& 4) (Russell and Sachs, 1992), aldolase (ald) (Kelley and Freeling, 1984b), alcohol dehydrogenase ( $a d h 1$ and $a d h 2$ ) (Dennis et al., 1985; Ferl et al., 1980; Gerlach et al., 1982; Rowland and Strommer, 1986; Sachs et al., 1980), Suc synthase (Springer et al., 1986), and lactate dehydrogenase (Good and Paetkau, 1992); their induction under $\mathrm{O}_{2}$-limited conditions in maize seedlings has been well characterized at the molecular level. There is also evidence for both transcriptional and translational regu- 
Table 2. Carbon dioxide evolution, ethanol production, and $\mathrm{O}_{2}$ uptake by maize root tips in $4 \% \mathrm{O}_{2}$ after $18 \mathrm{~h}$ hypoxic pretreatment. (Determinations were made as described in Hole et al., 1992.)

\begin{tabular}{lc}
\hline \hline Criterion & Quantity $\left(\mu \mathrm{mol} \cdot \mathrm{g}^{-1} \cdot \mathrm{h}^{-1}\right)$ \\
\hline $\mathrm{CO}_{2}$ evolved & $16.9 \pm 1.03$ \\
Ethanol production & $13.9 \pm 0.87$ \\
$\mathrm{O}_{2}$ uptake & $3.7 \pm 1.17$ \\
\hline
\end{tabular}

${ }^{\mathrm{z} F r e s h}$ weight basis.

lation (Bailey-Serres and Freeling, 1990; Bailey-Serres et al., 1988; McElfresh and Chourey, 1988; Sachs et al., 1980). Genes from the glycolytic pathway and the fermentation pathway share a consensus sequence in the promoter that may be required for anaerobic expression (Walker et al., 1987)

We have examined the induction of the glycolytic genes for aldolase (ald1) and enolase (enol) as well as for $a d h 1, a d h 2$, and $p d c$ from the ethanolic fermentative pathway in root tips of intact maize seedlings (Andrews et al., 1993, 1994b). In general, mRNAs from genes of the fermentative pathway were induced during hypoxia and showed a broadly similar pattern of expression. When expressed on the basis of relative induction, $a d h 2$ and $p d c$ were induced to a higher degree than adh1, enol, and aldl (Fig. 5). Both adh2 and $p d c$ reach a peak of induction at $12 \mathrm{~h}$ (16- and 13-fold, respectively). Adh2 declined to near the initial aerobic level by $18 \mathrm{~h}$. After the 18-h treatment, $p d c$ mRNA had declined below that of the initial aerobic level (data not shown). Adhl transcripts reached a maximum induction of $\approx 3$-fold at $6 \mathrm{~h}$ and had declined slightly by $18 \mathrm{~h}$ (Fig. 5). There was only slight induction of enol and aldl (Fig. 5). These transcripts are abundant under aerobic conditions, and further induction may not be as critical if the need for pyruvate under hypoxia does not exceed that needed under aerobic conditions. It is also important to note that mRNAs for all three genes specific for the ethanolic fermentative pathway were present, albeit in very low amounts, after the $40 \% \mathrm{O}_{2}$ pretreatment (time point 0 , Fig. 5).

During anoxia, HPT root tips had a greater induction of transcripts than did NHPT root tips (Fig. 6). Adh1 showed a slight increase of $\approx 3$ fold through $18 \mathrm{~h}$, then declined in HPT root tips, but declined throughout the treatment in NHPT root tips (Fig. 6). Adh2 transcripts in HPT root tips reached a maximum induction at $6 \mathrm{~h}, \approx 13$ fold over the initial aerobic level, and had declined to near 0 at $48 \mathrm{~h}$. In NHPT root tips, $a d h 2$ reached a maximum induction at $24 \mathrm{~h}$. Aldl was induced during anoxia in both HPT and NHPT root tips, although induction was greater and was maintained for a longer period of time in HPT root tips (Fig. 6). Neither $p d c$ nor enol was induced during anoxia in either HPT or NHPT root tips, and both declined through the duration of anoxia.

We have also examined how hypoxia and anoxia change the activity of the enzyme ADH (Andrews et al., 1993; Johnson et al., 1989,1994 ) and have recently extended this to PDC. During hypoxia, $\mathrm{ADH}$ and PDC activity increased throughout $18 \mathrm{~h}$ in root tips of intact seedlings. During anoxia, these same root tips showed a higher level of ADH and PDC activity through $96 \mathrm{~h}$ than did NHPT root tips (Johnson et al., 1989). In NHPT root tips, ADH1 activity peaked at 6 $\mathrm{h}$ of anoxia and declined thereafter (Andrews et al., 1993), whereas PDC activity was low at the onset of anoxia and did not increase.

Gauging the relative importance of $a d h l$ and $p d c$ in regulating ethanolic fermentation is of interest. Roberts et al. (1989), using a series of isogenic maize lines that differed in only ADH activity, showed that only a low level of $\mathrm{ADH}$ was necessary for survival so that the significance of the large increase in $\mathrm{ADH}$ activity remains unclear. Unacclimated $a d h 1$-null root tips will only survive 6 to $12 \mathrm{~h}$ of anoxia (Johnson et al., 1994; Roberts et al., 1984a, 1984b). However, adh1null root tips survived anoxia longer after hypoxic acclimation (Johnson et al., 1994). PDC increased linearly with time for the duration of hypoxia in intact root tips of wild type, and adhl-null and the concentration of PDC more closely paralleled ethanol production than did the concentration of ADH. This result suggests that regulation of pdc may play a key role in inducing fermentation.

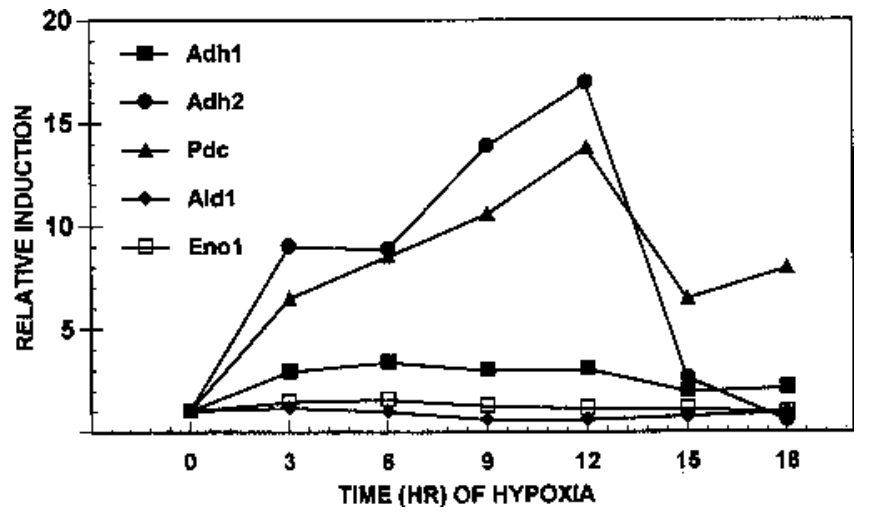

Fig. 5. Relative levels of $a d h 1, a d h 2, p d c$, ald1, and enol mRNA in root tips during hypoxia. Message levels are expressed relative to the level after the $40 \% \mathrm{O}_{2}$ pretreatment.

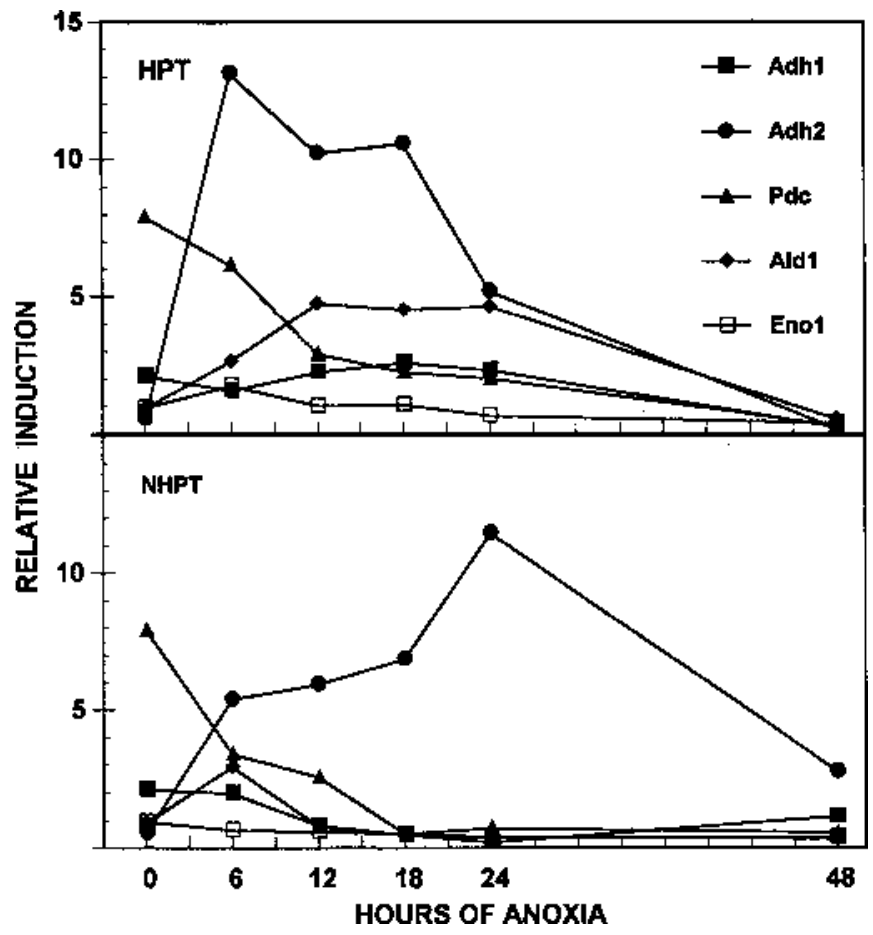

Fig. 6. Relative levels of $a d h 1$, adh2, pdc, ald1, and eno1 mRNA in root tips during anoxia of HPT and NHPT. Message levels are expressed relative to the level after the $40 \% \mathrm{O}_{2}$ pretreatment.

Evidence for induction of a lactate transport mechanism during hypoxia

A determinant of cell death under anoxia is cytoplasmic acidosis (Roberts et al., 1984a, 1984b). Davies (1980) first proposed that the initial production of lactate under anoxia results in a lowered cytosolic $\mathrm{pH}$, activates pyruvate decarboxylase and ethanolic fermentation, and inhibits lactate fermentation. Roberts et al. (1984a, 1984b) showed that, in unacclimated maize root tips, the cytosolic $\mathrm{pH}$ declined during the first 20 min of anoxia and then stabilized coincident with a burst of lactate production. Periods of anoxia longer than $10 \mathrm{~h}$ resulted in a further acidification of the cytoplasm and cell death.

The improved regulation of cellular $\mathrm{pH}$ following hypoxic acclimation may be attributed in part to the removal of lactate from the cells. Xia and Saglio (1992) and Xia and Roberts (1994) have shown that lactate is transported out of HPT root tips, whereas lactate accumulated in NHPT root tips. Xia and Roberts (1994) suggest that hypoxia may induce synthesis of a lactate transporter, thus minimizing cellular accumulation of lactate and cytoplasmic acidosis.

In contrast, Saint-Ges et al. (1991) have shown that cytosolic $\mathrm{pH}$ 
changes before lactate levels rise and the change in $\mathrm{pH}$ coincides with a decrease in ATP. Production of alanine and regulation of malate levels also are involved in regulation of cytoplasmic $\mathrm{pH}$ under conditions of low $\mathrm{O}_{2}$ (Roberts et al., 1992).

\section{CONCLUSIONS}

The procedures used to induce $\mathrm{O}_{2}$ deficit must be taken into consideration when comparing results from different laboratories. In many cases, the exact $\mathrm{O}_{2}$ concentration is not controlled and it is probable that some degree of acclimation has occurred in many of the studies of the anaerobic response in maize.

Maize seeds and young seedling roots are more resistant to anoxia than older seedlings. Older maize seedling roots require a hypoxic pretreatment to survive anoxia. This acclimation is associated with the induction of genes that are involved in ethanolic fermentation, thus allowing for ATP production during anoxia. Acclimation also appears to induce the transport of lactate from root cells, thus improving the regulation of the cytoplasmic $\mathrm{pH}$ during anoxia.

\section{Literature Cited}

Al-Ani, A., F. Bruzau, P. Raymond, V. Saint-Ges, J.M. Leblanc, and A. Pradet. 1985. Germination, respiration and adenylate energy charge of seeds at various oxygen partial pressures. Plant Physiol. 79:885-890.

Andrews, D.L., B.G. Cobb, J.R. Johnson, and M.C Drew. 1993. Hypoxic and anoxic induction of alcohol dehydrogenase in roots and shoots of seedlings of Zea mays: adh transcripts and enzyme activity. Plant Physiol. 101:407414.

Andrews, D.L., J.R. Johnson, M.C. Drew, and B.G. Cobb. 1994a. The response of maize seedlings of different ages to hypoxic and anoxic stress. Plant Physiol. 105:53-60.

Andrews, D.L., D.M. MacAlpine, J.R. Johnson, P.M. Kelley, and M.C. Drew. 1994b. Differential induction of mRNAs for the glycolytic and ethanolic fermentative pathways by hypoxia and anoxia in maize seedlings. Plant Physiol. 106:1575-1582.

Bailey-Serres, J. and M. Freeling. 1990. Hypoxic stress-induced changes in ribosomes of maize seedling roots. Plant Physiol. 94:1237-1243.

Bailey-Serres, J., B. Kloeckener-Gruissem, and M. Freeling. 1988. Genetic and molecular approaches to the study of the anaerobic response and tissue specific gene expression in maize. Plant Cell Environ. 11:351-357.

Blackwell, P. 1983. Measurements of aeration in waterlogged soils: Some improvements of techniques and their application to experiments using lysimeters. J. Soil Sci. 34:271-285.

Davies, D.D. 1980. Anaerobic metabolism and production of organic acids, $p$. 581-611. In: P.K. Stumph and E.E. Conn (eds.). The biochemistry of plants: A comprehensive treatise. vol. 2. Academic, New York.

Dennis, E.S., M.M. Sachs, W.L. Gerlach, E.J. Finnegan, and W.J. Peacock. 1985. Molecular analysis of the alcohol dehydrogenase 2 (Adh2) gene of maize. Nucleic Acids Res. 13:727-743.

Drew, M.C. 1988. Effects of flooding and oxygen deficit on plant mineral nutrition, p. 115-159. In: A. Läuchli and P.B. Tinker (eds.). Advances in plant nutrition. vol. 3. Praeger, New York.

Ferl, R.J., M. Brennan, and D. Schwartz. 1980. In vitro translation of maize ADH: Evidence for the anaerobic induction of mRNA. Biochem. Genet. 18:681-691.

Freeling, M. and D.C. Bennett. 1985. Maize Adh1. Annu. Rev. Genet. 19:297323.

Gerlach, W.L., A.J. Pryor, E.S. Dennis, R.J. Ferl, M.M. Sachs, and W.J. Peacock. 1982. cDNA cloning and induction of the alcohol dehydrogenase (Adhl) gene of maize. Proc. Natl. Acad. Sci. USA 79:2981-2985.

Good, A.G. and D.H. Paetkau. 1992. Identification and characterization of a hypoxically induced maize lactate dehydrogenase gene. Plant Mol. Biol. 19:693-697.

Hole, D.J., B.G. Cobb, P.S. Hole, and M.C. Drew. 1992. Enhancement of anaerobic respiration in root tips of Zea mays following low-oxygen (hypoxic) acclimation. Plant Physiol. 99:213-218.

Hwang, S. and T. VanToai. 1991. Abscisic acid induces anaerobiosis tolerance in corn. Plant Physiol. 97:593-597.

Jackson, M.B. and M.C. Drew. 1984. Effects of flooding on growth and metabolism of herbaceous plants, p. 47-128. In: T.T. Koslowski (ed.). Flooding and plant growth. Academic, Orlando, Fla.

Johnson, J., B.G. Cobb, and M.C. Drew. 1989. Hypoxic induction of anoxia tolerance in roots in Zea mays. Plant Physiol. 91:837-841.

Johnson, J.R., B.G. Cobb, and M.C. Drew. 1994. Hypoxic induction of anoxia tolerance in roots of Adh1 null Zea mays L. Plant Physiol. 105:61-67.

Kelley, P.M. 1989. Maize pyruvate decarboxylase mRNA is induced anaerobically. Plant Mol. Biol. 13:213-222.

Kelley, P.M. and M. Freeling. 1984a. Anaerobic expression of maize glucose phosphate isomerase I. J. Biol. Chem. 259(1):673-677.

Kelley, P.M. and M. Freeling. 1984b. Anaerobic expression of maize fructose1, 6-diphosphate aldolase. J. Biol. Chem. 259(22):14,180-14,183.

Kennedy, R.A., M.E. Rumpho, and T.C. Fox. 1992. Anaerobic metabolism in plants. Plant Physiol. 100:1-6.

Laszlo, A. and P.S. Lawrence. 1983. Parallel induction and synthesis of PDC and ADH in anoxic maize roots. Mol. Gen. Genet. 192:110-117.

Leblova, S. 1978. Pyruvate conversions in higher plants during natural anaerobiosis, p. 581-611. In: D.D. Hook and R.M.M. Crawford (eds.). Plant life in anaerobic environments. Ann Arbor Science, Ann Arbor, Mich.

McElfresh, K.C. and P.S. Chourey. 1988. Anaerobiosis induces transcription but not translation of sucrose synthase in maize. Plant Physiol. 87:542-546.

Peschke, V. and M.M. Sachs. 1994. Characterization and expression of transcripts induced by oxygen deprivation in maize (Zea mays L.). Plant Physiol. 104:387-394.

Pradet, A. and J.L. Bomsel. 1978. Energy metabolism in plants under hypoxia and anoxia, p. 89-118. In: D.D. Hook and R.M.M. Crawford (eds.). Plant life in anaerobic environments. Ann Arbor Science, Ann Arbor, Mich.

Raymond, P., A. Al-Ani, and A. Pradet. 1985. ATP production by respiration and fermentation, and energy charge during aerobiosis and anaerobiosis in twelve fatty and starch germinating seeds. Plant Physiol. 79:879-884.

Ricard, B., I. Couée, P. Raymond, P.H. Saglio, V. Saint-Ges, and A. Pradet. 1994. Plant metabolism under hypoxia and anoxia. Plant Physiol. Biochem. 32:1-10.

Roberts, J.K.M., J. Callis, O. Jardetsky, V. Walbot, and M. Freeling. 1984a. Cytoplasmic acidosis as a determinant of flooding intolerance in plants. Proc. Natl. Acad. Sci. USA 81:6029-6033.

Roberts, J.K.M., J. Callis, O.D. Wemmer, V. Walbot, and O. Jardetzky. 1984b. Mechanism of cytoplasmic $\mathrm{pH}$ regulation in hypoxic maize root tips and its role in survival under hypoxia. Proc. Natl. Acad. Sci. USA 81:3379-3383.

Roberts, J.K.M., K. Chang, C. Webster, J. Callis, and V. Walbot. 1989. Dependence of ethanolic fermentation, cytoplasmic $\mathrm{pH}$ regulation and viability on the activity of alcohol dehydrogenase in hypoxic maize root tips. Plant Physiol. 89:1275-1278.

Roberts, J.K.M., M.A. Hooks, A.P. Miaullis, S. Edwards, and C. Webster. 1992. Contribution of malate and amino acid metabolism to cytoplasmic $\mathrm{pH}$ regulation in hypoxic maize root tips: Studies using nuclear magnetic resonance spectroscopy. Plant Physiol. 98:480-487.

Rowland, L.J. and J.N. Strommer. 1986. Anaerobic treatment of maize roots affects transcription of Adhl and transcript stability. Mol. Cell Biol. 6:3368-3372.

Russell, D. and M.M. Sachs. 1992. Protein synthesis in maize during anaerobic and heat stress. Plant Physiol. 99:615-620.

Sachs, M.M., E.S. Dennis, J. Ellis, E.J. Finnegan, W.L. Gerlach, D. Llewellyn, and W.J. Peacock. 1985. Adh1 and Adh2: Two genes involved in the maize anaerobic response, p. 217-226. In: J. Key and T. Kosuge (eds.). Cellular and molecular biology of plant stress. vol. 22. Liss, New York.

Sachs, M.M., M. Freeling, and R. Okimoto. 1980. The anaerobic proteins of maize. Cell 20:761-767.

Saglio, P.H., M.C. Drew, and A. Pradet. 1988. Metabolic acclimation to anoxia induced by low (2-4 kPa partial pressure) oxygen pretreatment (hypoxia) in root tips of Zea mays. Plant Physiol. 86:61-66.

Saglio, P.H., M. Rancillac, F. Bruzau, and A. Pradet. 1984. Critical oxygen pressure for growth and respiration of excised and intact roots. Plant Physiol. 76:151-154.

Saglio, P.H., P. Raymond, and A. Pradet. 1980. Metabolic activity and energy charge of excised maize root tips under anoxia. Plant Physiol. 66:10531057.

Saint-Ges, V., C. Roby, R. Bligny, A. Pradet, and R. Douce. 1991. Kinetic studies of the variations of cytoplasmic $\mathrm{pH}$, nucleotide triphosphates $\left({ }^{31} \mathrm{P}-\right.$ NMR) and lactate during normoxic and anoxic transitions in maize root tips. Eur. J. Biochem. 200:477-482.

Smith, A.M. and T. Ap Rees. 1979. Pathways of carbohydrate fermentation in the roots of marsh plants. Planta 146:327-334.

Springer, B.W., P. Werr, D.C. Starlinger, M. Bennett, M. Zokolica, and M. Freeling. 1986. The Shrunken gene on chromosome 9 of Zea mays L. is expressed in various plant tissues and encodes an anaerobic protein. Mol. Gen. Genet. 205:461-468.

Walker, J.C., E.A. Howard, E.S. Dennis, and W.J. Peacock. 1987. DNA sequences required for anaerobic expression of the maize alcohol dehydrogenase gene. Proc. Natl. Acad. Sci. USA 84:6624-6628.

Xia, J.H. and J.K.M. Roberts. 1994. Improved cytoplasmic pH regulation, increased lactate efflux, and reduced cytoplasmic lactate levels are biochemical traits expressed in root tips of whole maize seedlings acclimated to a low-oxygen environment. Plant Physiol. 105:651-657.

Xia, J.H. and P.H. Saglio. 1992. Lactic acid efflux as a mechanism of hypoxic acclimation of maize root tips to anoxia. Plant Physiol. 100:40-46. 